\title{
A CULTURA DA INOVAÇÃO EM UMA MÉDIA EMPRESA DO SETOR AUTOMOBILÍSTICO
}

Mario Henrique Jorge ${ }^{1}$

Marcela Barbosa De Moraes ${ }^{1}$

Francisco Kenedy Quinderé Aquino ${ }^{1}$

${ }^{1}$ UNIVERSIDADE DE TAUBATÉ (UNITAU) 


\section{A CULTURA DA INOVAÇÃO EM UMA MÉDIA EMPRESA DO SETOR AUTOMOBILÍSTICO}

Resumo: O objetivo deste trabalho é analisar as principais características da cultura da inovação percebidas pelos colaboradores de uma indústria do setor automobilístico. Para a realização deste estudo a metodologia de pesquisa adotada é a survey, com a aplicação de um questionário semiestruturado com base em dados obtidos na análise estatística e fatorial. A análise se realizou em duas fases: na primeira efetuou-se o cálculo do alfa de Cronbach e do KMO para verificar a confiabilidade da amostra; na segunda fase corresponde à análise fatorial, verificando-se a relação das variáveis mensuráveis com as variáveis latentes. Constatou-se que a cultura da inovação está implementada e tornou-se parte da cultura organizacional da empresa. A cultura da inovação é utilizada como estratégia de desenvolvimento tecnológico, para que possa tornar-se fator gerador de inovação tecnológica, podendo trazer, ao longo do tempo, vantagens competitiva, estratégica e econômica para a empresa.

Palavras-chave: Inovação. Cultura da Inovação. Média Empresa. Setor Automobilístico.

\section{$1 \quad$ Introdução}

A inovação tecnológica tem contribuído para a evolução econômica das empresas e tornou-se para muitas empresas a principal estratégia competitiva de manutenção e crescimento de mercado, gerando vantagem competitiva e contribuindo para o desenvolvimento sustentável entre o capital e a natureza (ABRAMOVAY, 2012).

As organizações podem obter diversos benefícios com a inovação, agregando valor aos produtos, aumentando sua participação comercial, trazendo melhores números de crescimento, podendo, assim, obter a maximização de seus resultados financeiros (WITELL et al., 2010).

O conceito inovação, segundo o Manual de Oslo, é a implementação de um produto, processo, bem ou serviço novo ou significativamente aperfeiçoado, ou um novo método de marketing, ou um novo método organizacional nas práticas de negócios, nas organizações do local de trabalho ou nas relações externas (OECD, 2006).

A cultura de inovação é compreendida como a distribuição de valores e crenças por indivíduos que integram uma organização a respeito da inovação, aliada à ideia de busca de competitividade. Segundo Moraes et. al (2017, p.441), "a concepção da cultura da inovação tem chamado a atenção de muitos estudiosos e profissionais de diversas áreas de conhecimento".

A cultura da inovação tem sido definida com um contexto multidimensional, que inclui infraestrutura, comportamento e meio ambiente, fatores que facilitam o surgimento da inovação tecnológica na organização (DOBNI, 2008).

Com a intenção de colaborar com os estudos sobre a cultura da inovação, este trabalho busca analisar as principais características dessa cultura, percebidas pelos colaboradores de uma indústria do setor automobilístico. 


\section{$2 \quad$ Referencial Teórico}

\subsection{Perspectivas teóricas da inovação}

A origem do conceito de inovação pode ser creditada aos estudos do economista austríaco Schumpeter (1883-1950), a inovação para Schumpeter é o fenômeno fundamental de uma economia capitalista e a inovação é uma força destrutiva que desconstrói as condições atuais do mercado e, ao mesmo tempo, cria novas condições mercadológicas a partir de novas combinações, gerando o produto da inovação, que é o desenvolvimento.

Conceitua-se a inovação como a adoção de métodos de produção novos ou significativamente melhorados, incluindo os métodos de entrega dos produtos. Tais métodos podem envolver mudanças no equipamento ou na organização da produção, ou uma combinação dessas mudanças, e pode derivar do uso do novo conhecimento (OCDE, 2006).

Pode-se compreender a inovação como uma estratégia focada no resultado de um processo econômico, nessa perspectiva, a geração da inovação teve ter a sua gestão de natureza transversal, e o método de abordagem precisa incorporar o diálogo com diversas áreas do conhecimento, caminhando em direção à interdisciplinaridade (TIGRE,2006).

As empresas contemporâneas buscam criar valor com seus clientes e com outras empresas, utilizando de estratégias de inovação para otimizar seus recursos. Uma dessas estratégias é a inovação aberta, uma estratégia que reconhece que ideias internas podem ser levadas para o mercado por meio de canais externos que não pertencem ao core business da empresa. A inovação aberta pode ser definida como a busca de novos conhecimentos, processos, ideias e tecnologias, independentemente de sua localização. (CHESBROUGH, 2003a, 2006, 2007).

A partir dessas definições percebe-se que a inovação, mais do que apenas um conceito, deve ser a estratégia mais apropriada quando da necessidade da manutenção dos bons resultados ou de uma diferenciação em meio à concorrência. Introduziremos a seguir sobre as perspectivas teóricas da cultura da inovação.

\subsection{Perspectivas teóricas da cultura da inovação}

Os estudos da cultura de inovação começaram a ser realizados no universo organizacional no início dos anos 2000, com o propósito de identificar os elementos que compõem um ambiente propício à inovação, que são as entradas para a geração de inovação tecnológica (SABAINI,2013).

Janiunaite e Petraite (2010, p. 15) definem, que "a cultura da inovação é um grande conjunto de características que compõem a cultura organizacional de uma empresa, e que buscam facilitar as atividades inovadoras". A cultura das organizações é composta por um conjunto de diversos processos, valores, metas, objetivos, práticas de comunicação, crenças e atitudes.

A percepção dos colaboradores em relação à cultura da inovação colabora para a adequação do negócio da empresa, ajudando a desenvolver diversos fatores, como: competências, aspectos comportamentais, ambientes existentes, processos, recursos disponíveis e estratégias usadas (MORAES et al.,2017). 
Dobni (2008, p.541), propôs um modelo de cultura de inovação que se torna fonte geradora de desempenho organizacional, o que se pode ver na Figura 1, mostra o modelo teórico proposto, que utiliza a análise fatorial exploratória como método de análise.

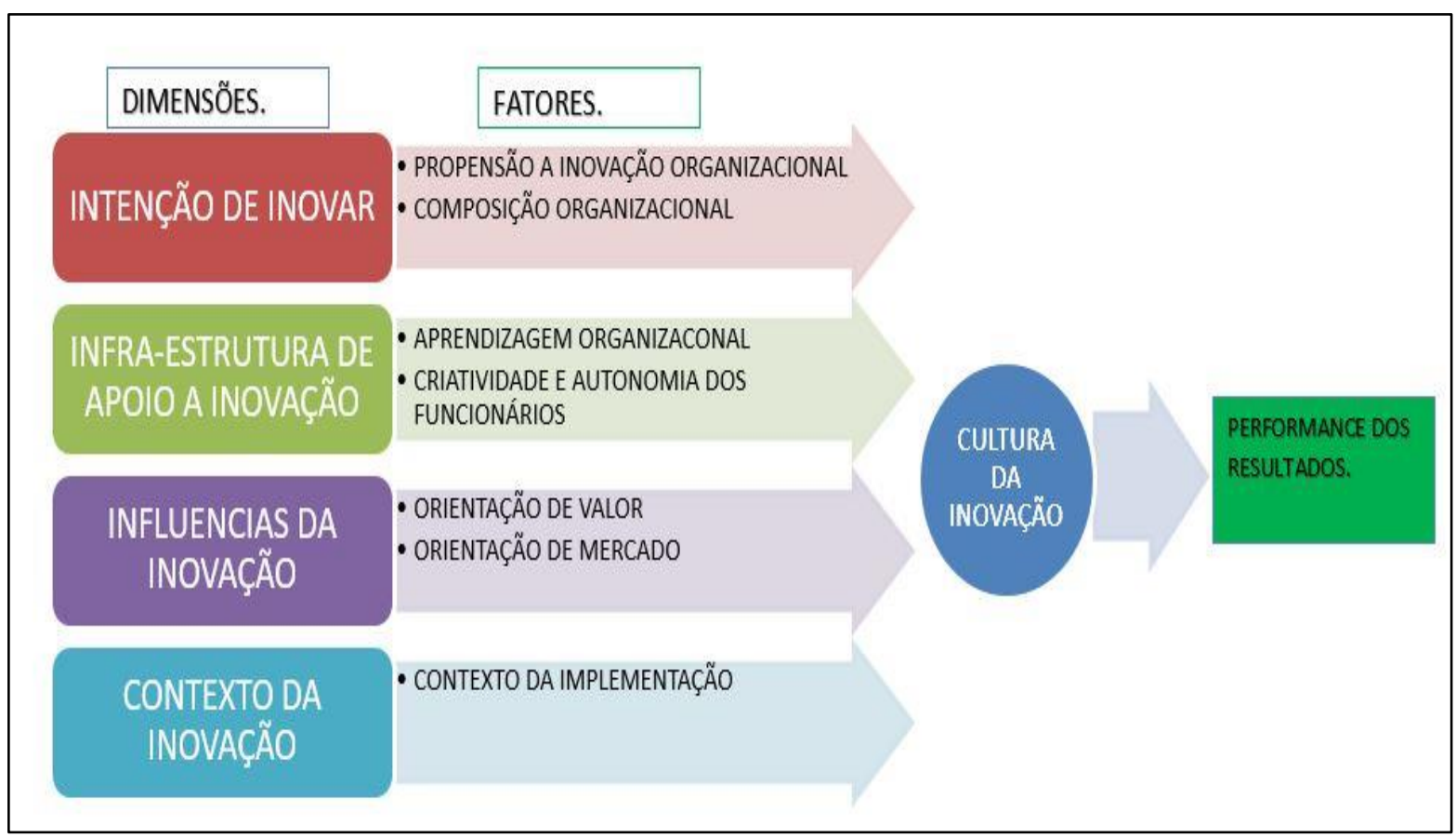

Figura 1 - Modelo de Cultura de Inovação

Fonte: adaptada de Dobni (2008, p. 541).

O modelo criado por Dobni, para o estudo da cultura da inovação será o marco teórico deste estudo, sendo composto por quatro dimensões que são: a intenção de ser inovador; a infraestrutura que dará suporte à inovação; o conhecimento e orientação aos empregados para dar suporte aos pensamentos e ligações necessários à inovação; e um ambiente ou contexto para dar suporte à implementação, que invariavelmente tem risco inerente e recompensas em troca. Esses estudos de Dobni mostram uma forma validada e já aplicada de confirmar o empenho de uma organização em criar inovação e ter uma cultura inovadora implementada.

\subsection{As empresas automobilísticas do Brasil e a inovação}

A evolução tecnológica está inserida na cultura organizacional das empresas automotivas, desde os seus primórdios os veículos evoluíram de modelos movidos a energia a vapor, no século XIX, até os carros movidos a nitrogênio e à eletricidade no século XXI.

Segundo Morem (2016), no setor automobilístico brasileiro há empresas que atuam apenas na produção de um tipo de veículo, como a Audi, com automóveis de luxo, e outras que operam em mais de um nicho, como a Volkswagen, com automóveis, comerciais leves, caminhões e ônibus. As montadoras no Brasil têm fábricas destinadas a todos os tipos de veículos. Quanto ao tamanho, as montadoras e suas fornecedoras de primeiro nível, denominadas Tier One, são consideradas empresas de grande porte em relação à cadeia 
industrial brasileira, pela alta tecnologia envolvida em seu processo e grande mercado atendido.

O setor automobilístico é importante na geração de inovação e desenvolvimento de técnicas de competividade. Esse setor econômico está constantemente recebendo fortes investimentos em produtos e automação de processos que geraram mudanças significativas nesse setor, fazendo com que a inovação seja estratégica (WOOD JR; CALDAS, 2007).

As inovações aplicadas aos veículos apresentaram importante impacto na competitividade do setor e contribuíram para os players dominantes do mercado, que criou novo cenário no setor automobilístico brasileiro, propiciando um ganho de competividade no âmbito internacional (BARQUETTE; COSTA, 2017).

Ao finalizar esse tópico pode-se compreender a abrangência econômica da indústria automobilística, o impacto da geração de inovação nesse setor econômico, e as vantagens que podem ser obtidas quando se tem a cultura de inovação implementada.

\section{$3 \quad$ Procedimento Metodológico}

Esta pesquisa é de abordagem quantitativa, que consiste em uma investigação empírica, cuja principal finalidade é o delineamento ou análise das características de fatos ou fenômenos e avaliação de programas ou o isolamento de variáveis principais ou chaves. Quanto ao objetivo a pesquisa é descritiva, que segundo Perez $(2009, \mathrm{p} .187)$ visa descrever as características de uma determinada população, fenômeno, ou verificar a existência de relações entre variáveis.

A pesquisa descritiva envolve o uso de técnicas padronizadas de coleta de dados, na realização desta pesquisa utilizou-se o método de survey, que envolve um questionário estruturado aplicado em uma amostra da população e destinado a obter informações específicas das pessoas entrevistadas. A população a ser estuda é composta por 107 funcionários da empresa estudada que atuam nas suas seis plantas produtivas, nos times de engenharia, que foram escolhidos por causa da sua interação com os clientes e desenvolvimento de novos produtos e ou processos.

O instrumento utilizado foi desenvolvido por Dobni (2008), que conforme Moraes et al. (2017) foi construído por fatores que têm influência na cultura de inovação. Esse mesmo instrumento foi replicado pelos autores para verificar a cultura de inovação em micro e pequenas empresas do setor aeronáutico e tecnologia da informação.

O instrumento desenvolvido por Dobni (2008) trabalha com quatro dimensões que são utilizadas para medir a cultura de inovação nas organizações. As dimensões foram divididas em sete fatores.

$>$ A dimensão da intenção de inovar envolve dois fatores: i) a propensão à inovação organizacional, que fala o quanto formalmente a organização está propensa a obter a inovação; e ii) o fator da composição organizacional que vai avaliar se os funcionários têm motivação para inovar e se são recompensados por isso.

> A segunda dimensão trata da infraestrutura de apoio à inovação e também envolve dois fatores: i) a aprendizagem organizacional, que avalia se a organização prepara e foca os treinamentos de seus colaboradores em busca da inovação tecnológica; e ii) a criatividade e autonomia dos funcionários, que avalia qual o grau de decisão e a liberdade que os funcionários têm para inovar. 
As influências da inovação é a terceira dimensão, que traz como fator i) a orientação de valor, que mensura o quanto os colaboradores da empresa conhecem o que seus clientes esperam da empresa; e ii) trabalha o fator de orientação de mercado, que verifica qual o nível de conhecimento que os colaboradores da empresa têm de seus concorrentes.

$>$ A última dimensão é o contexto da inovação, com o fator contexto da implementação. Utilizam-se questões que apontam os rumos atuais da inovação na empresa e como ela se prepara para o futuro.

$>\mathrm{O}$ instrumento foi replicado nesta pesquisa e os fatores presentes foram chamados de variáveis latentes, pois são constructos hipotéticos que não podem ser mensurados diretamente.

As variáveis latentes ou dimensões são representadas por múltiplas variáveis que servem como indicadores para geração dos constructos, denominadas variáveis mensuráveis. Os dados obtidos após a realização da pesquisa, utilizando o instrumento desenvolvido por Dobni (2008), foram tabulados e por serem formados por variáveis independentes optou-se por analisá-los posteriormente, pela modelagem de equações estruturais.

Após a coleta, foi feita a análise dos dados em duas etapas distintas: $1^{\text {a }}$ ) Teste de Confiabilidade alfa de Cronbach e Teste de Kaiser-Meyer-Olkin (KMO); $2^{a}$ ) Análise Fatorial Confirmatória. Os cálculos foram efetuados no software SPSS 22.

\section{$4 \quad$ Resultados e Discussões}

Inicialmente efetuou-se a análise do alfa de Cronbach, para mensurar o nível de confiabilidade, e o teste de Kaiser-Meyer-Olkin (KMO) para verificar se os dados obtidos eram adequados à aplicação da análise fatorial. Utilizou-se o alfa de Cronbach para mensurar o nível de confiabilidade, que é apresentado na Tabela 1.

\section{Tabela 1 - Análise do alfa de Cronbach}

\begin{tabular}{lc}
\hline \multicolumn{1}{c}{ Dimensões da cultura da inovação } & Alfa de Cronbach \\
\hline Propensão a Inovação Organizacional & 0,839 \\
Composição Organizacional & 0,936 \\
Aprendizagem Organizacional & 0,941 \\
Criatividade e Autonomia dos Funcionários & 0,823 \\
Orientação de Valor & 0,899 \\
Orientação para o Mercado & 0,858 \\
Contexto Organizacional & 0,938 \\
\hline
\end{tabular}

Fonte: Elaborado pelos autores

De acordo com Hair et. al (2012), o limite inferior para uma escala ser considerada confiável é de 0,7. Após a análise pelo alpha de Cronbach verificou-se se os dados obtidos eram adequados para a aplicação da análise fatorial. Utilizou-se, então, o teste Kaiser-Meyer- 
Olkin (KMO), que indica qual é o grau de suscetibilidade ou de ajuste dos dados à análise fatorial (HAIR et. al, 2012).

Tabela 2 - Análise do KMO

\begin{tabular}{lc}
\multicolumn{1}{c}{ Dimensões da Cultura da Inovação } & KMO \\
\hline Propensão a Inovação Organizacional & 0,870 \\
Composição Organizacional & 0,898 \\
Aprendizagem Organizacional & 0,921 \\
Criatividade e Autonomia dos Funcionários & 0,865 \\
Orientação de Valor & 0,867 \\
Orientação para o Mercado & 0,808 \\
Contexto Organizacional & 0,887 \\
\hline
\end{tabular}

Fonte: Elaborado pelos autores

Os dados da Tabela 2 mostram que o KMO variou entre 0,808 e 0,921 , evidenciando que os valores obtidos no teste são adequados para a análise fatorial. Após a análise do KMO, realizou-se a análise estatística descritiva das dimensões da cultura de inovação.

\subsection{Análise fatorial das dimensões da cultura da inovação}

A relação direta entre cada variável observável nesta pesquisa responde pela carga externa e foi denominada variável mensurável. Já a variável latente é aquela hipotética ou teórica que não pode ser diretamente medida nesta pesquisa evidenciada pelos fatores da cultura de inovação, mas pode ser representada por outros indicadores constituídos pelos itens das escalas ou pela observação do pesquisador, que em conjunto permitirão que se obtenha uma medida razoavelmente precisa da atitude (HAIR et. al,2012).

A variável observada é mensurável e é a que deve usada para medir a variável latente. Como parâmetro se utilizará uma relação casual perfeita entre ambas de 1:1, ou seja, quanto mais próxima de 1,00, a variável mensurável exerce uma ação com efeito mais relevante na variável latente.

As variáveis mensuráveis demonstram que a empresa tem uma visão de inovação e está alinhada aos projetos, e que seus superiores transmitem efetivamente a mensagem da inovação. Essas variáveis são as que promovem maior interação com a variável latente de propensão à inovação, com um grau de relação acima de 0,812 .

Esses resultados confirmam o conceito de que a inclusão da inovação na estratégia da organização é o passo inicial para demonstrar seu comprometimento com a inovação (MARTINS; TERBLANCHE, 2003). Os dados são mostrados na Tabela 3 e mostram que a maior parte das variáveis mensuráveis apresenta um bom índice de relação com a variável latente.

A variável mensurável que mede as opiniões diferentes dos gestores sobre como as atividades são desenvolvidas obteve uma relação com valor de 0,355 , evidenciando que a empresa pode trabalhar seus gestores para que possam estar mais alinhados para desenvolver seus projetos. 
Tabela 3 - Variável Latente de Propensão a Inovação - Carga Externa Variavel Latente de Propensão a Inovação

\begin{tabular}{lrr}
\hline Variável Mensurável & Carga Externa & Grau de Influência \\
\hline A empresa tem uma visão de inovação que está alinhada aos projetos. & 0,815 & 1 \\
Os meus superiores transmitem efetivamente a mensagem da inovação & 0,812 & 2 \\
Na minha empresa o modelo de negócios permite uma visão estratégica. & 0,743 & 3 \\
Na empresa há coerência entre as metas de inovação e os objetivos. & 0,722 & 4 \\
A empresa promove iniciativas de inovar entre os funcionários. & 0,701 & 5 \\
A inovação tem um valor fundamental na minha empresa & 0,645 & 6 \\
As atividades no planejamento da empresa são focadas no mercado. & 0,577 & 7 \\
Em minha opinião, inovação é uma cultura e não uma palavra. & 0,458 & 8 \\
A gestão tem opiniões diferentes sobre como as coisas são feitas. & 0,355 & 9 \\
\hline
\end{tabular}

Fonte: Elaborado pelos autores

No estudo realizado por Dobni (2008) essa variável obteve o valor 0,511, mostrando que para os funcionários do setor bancário do Canadá, o alinhamento das opiniões dos gestores já está em um grau de desenvolvimento maior do que os gestores da empresa automobilística aqui analisada.

A observação das demais variáveis latentes apontou que a variável composição organizacional teve boa relação com as variáveis mensuráveis ligadas à valorização e confiança dos colaboradores da empresa com a sua supervisão, destacando que confiam em seus gestores. A relação dessas variáveis superou 0,828.

Esse resultado demostra que a empresa busca desenvolver a confiança entre colaboradores e gestores, e trabalha o conceito de quem tem a intenção como um de seus elementos essenciais e a confiança dos colaboradores com a supervisão, colabora para que possa ter mais oportunidades de mostrar a sua criatividade (QUINN, 2005). Os dados são demonstrados na Tabela 4.

Tabela 4 - Variável latente de composição organizacional - Carga Externa Variável Latente de Composição Organizacional

\begin{tabular}{lrr}
\hline Pergunta & Carga Externa & Grau de Influência \\
\hline Eu sinto confiança nos meus superiores. & 0,831 & 1 \\
Eu me sinto valorizado pelos meus superiores. & 0,828 & 2 \\
Há confiança mútua entre funcionários e gerentes. & 0,822 & 3 \\
Eu me sinto recompensado pelas atividades que desempenho. & 0,786 & 4 \\
Na minha empresa a comunicação é aberta e honesta. & 0,784 & 5 \\
Os funcionários são tratados igualmente e isso é evidente. & 0,781 & 6 \\
Eu geralmente tenho ideias que são aproveitadas na empresa. & 0,761 & 7 \\
Sou encorajado a mudar ações e decisões na minha empresa. & 0,755 & 8 \\
Na minha empresa os funcionários podem se expressar e participar. & 0,745 & 9 \\
Eu estou conectado com as mudanças e assim inovo na empresa. & 0,745 & 9 \\
O ambiente é de colaboração entre os departamentos. & 0,637 & 10 \\
As contribuições são valorizadas pelos meus colegas de empresa. & 0,630 & 11 \\
Eu sei como posso contribuir para a inovação na minha empresa. & 0,628 & 12 \\
Minha empresa motiva por meio de recompensas não financeiras. & 0,604 & 13 \\
Eu sou responsável por criar o futuro da empresa. & 0,597 & 14 \\
Os funcionários da minha área agem como um time. & 0,570 & 15 \\
Estou envolvido no planejamento estratégico da minha empresa. & 0,527 & 16 \\
Minha empresa motiva por meio de recompensas financeiras. & 0,493 & 17 \\
\hline
\end{tabular}

Fonte: Elaborado pelos autores

A variável mensurável que verificava se as contribuições são valorizadas pelos colegas da empresa, e a variável mensurável referente à colaboração entre os departamentos 
obtiveram grau de influência com valores similares com inter-relação, destacando a importância de trabalhar as contribuições individuais e as coletivas entre os colaboradores.

Esse fato reflete diretamente no conceito de cocriação de valor, que é uma forma de inovação em que colaboradores e clientes associam-se ao negócio ou produto, agregando e gerando inovação tecnológica (RAMASWAMY, 2009).

A variável mensurável que media se a empresa motivava os funcionários com recompensas financeiras obteve um grau de relação de 0,493. É um ponto de melhoria para a empresa não ter como foco incentivar financeiramente seus funcionários a inovar. Essa variável não tem um grau de influência alto na variável latente composição organizacional.

Esse resultado está alinhado com o estudo de Dobni (2008), no qual essa variável mensurável apresentou um valor de 0,508, demonstrando que recompensar financeiramente os funcionários não é aplicado tanto no setor bancário estudado por Dobni, como na empresa automobilística estudada neste trabalho.

A variável latente de aprendizagem organizacional apresenta boa relação com todas as suas variáveis mensuráveis, estando todos os valores acima de 0,541. A variável mensurável que mede se na empresa existe orientação após a realização dos treinamentos, com a relação em 0,908, mostrou que a empresa busca dar importância do conhecimento técnico, e para gerar a inovação adquirir conhecimento técnico é essencial para transformar ideias em atos concretos e, portanto, propiciar a geração da inovação (MUMFORD; LICUANAN, 2004).

A variável mensurável que mensurou se os líderes têm as qualidades de liderança para inovar obteve uma carga externa de 0,742. Essa variável apresentou valor bem similar à variável que mediu se os gerentes auxiliam os treinamentos de formação dos funcionários.

Os dados levantados pelas respostas dos colaboradores para a variável latente de aprendizagem organizacional são mostrados na Tabela 5.


Variável Latente de Aprendizagem Organizacional

\begin{tabular}{lcc}
\hline Variável Mensurável & Carga Externa & Grau de Influência \\
\hline Existe na empresa orientação após a realização de treinamentos. & 0,908 & 1 \\
Há na empresa desenvolvimento de novas habilidades para a inovação. & 0,853 & 2 \\
Participo de treinamento para apoiar a inovação da empresa. & 0,848 & 3 \\
Sou encorajado a aplicar o conhecimento que recebo. & 0,823 & 4 \\
Os treinamentos são direcionados para o valor entregue ao cliente. & 0,810 & 5 \\
A aprendizagem é incentivada gerando melhorias nas competências. & 0,788 & 6 \\
Na empresa há reuniões para discutir situações de aprendizagem. & 0,788 & 6 \\
Os treinamentos da empresa auxiliam as iniciativas estratégicas. & 0,758 & 7 \\
Os gestores possuem as qualidades de liderança para inovar. & 0,742 & 8 \\
Os gerentes auxiliam os treinamentos de formação dos funcionários. & 0,737 & 9 \\
Eu sei descrever as competências da minha função. & 0,589 & 10 \\
A empresa está preparada para detectar mudanças de mercado. & 0,541 & 11 \\
\hline
\end{tabular}

Fonte: Elaborado pelos autores

O resultado obtido para o contexto da inovação mostra, conceitualmente, que na empresa estudada desenvolver a liderança para inovar e criar um ambiente propício para isso, desenvolvendo treinamentos de forma a conduzir os colaboradores a gerar a inovação, é um fator trabalhado na organização (MONTEIRO, 2008). 
Observou-se que para a variável mensurável que mede se a empresa está preparada para detectar as mudanças do mercado, com 0,541 , obteve um resultado mais significativo para a empresa estudada do que no estudo de Dobni (2008).

O autor encontrou nessa variável mesurável o valor para variável latente de 0,301, demonstrando que as empresas no seguimento bancário necessitavam se preparar melhor para detectar as mudanças em seus mercados de atuação e não serem surpreendidas pela concorrência.

Em relação à variável latente criatividade e autonomia dos funcionários, o grau de relação encontrado foi significativo com suas sete variáveis mensuráveis, com valores acima de 0,645 .

A variável mensurável que mediu se os funcionários têm liberdade e estão autorizados a expressar ideias, e a variável mensurável que verificou se os funcionários têm oportunidade de desenvolver potencial criativo, obtiveram o maior incremento nessa variável latente, pois propiciar autonomia para expressar ideias é um fator gerador de inovação tecnológica.

Esse resultado mostra que a liberdade e autonomia dos empregados para assumir riscos, propondo metas desafiadoras e decidam como alcançá-las promove a realização pessoal e o comprometimento com os objetivos da organização e a geração de inovações (AMABILE et. al, 2005). A Tabela 6 traz os resultados.

\section{Tabela 6 - Variável latente de criatividade e autonomia - Carga Externa}

\section{Variável Latente de Criatividade e Autonomia dos Funcionários}

\begin{tabular}{lcr}
\hline Variável Mensurável & Carga Externa & Grau de Influência \\
\hline Os funcionários têm liberdade e estão autorizados a expressar ideias. & 0,786 & 1 \\
Tenho oportunidade de desenvolver meu potencial criativo. & 0,735 & 2 \\
Estou preparado para fazer as coisas de forma diferente. & 0,708 & 3 \\
Eu me considero uma pessoa criativa e inovadora dentro da empresa. & 0,689 & 4 \\
Eu vejo a incerteza como uma oportunidade e não como um risco. & 0,663 & 5 \\
A minha empresa utiliza a minha criatividade para ter benefícios. & 0,663 & 5 \\
Meu supervisor valoriza meu potencial criativo e com isso me estimula. & 0,645 & 6 \\
\hline
\end{tabular}

Fonte: Elaborado pelos autores

Verificou-se que a variável mensurável que avalia se a supervisão valoriza o potencial criativo, e se isso estimula os colaboradores, foi a que apresentou o maior potencial de aprimoramento, mostrando que é possível um trabalho junto à liderança para valorizar de forma mais eficiente os colaboradores e/ou melhorar o processo de valorização por parte da liderança.

A análise da variável latente orientação de valor mostrou que o grau de relação com as variáveis mensuráreis é excelente, o que denota a importância de a empresa criar valor com seus clientes, utilizando essa interação para alcançar resultados com mais velocidade e produzindo produtos alinhados com as necessidades dos clientes.

Outra afirmação da importância dessa variável latente para a cultura de inovação foi o grau de relação de 0,842 obtido na variável mensurável que mediu se existe um consenso entre os funcionários e os gestores para a criação do valor.

O sucesso das inovações tecnológicas pode estar sujeito ao entendimento dos objetivos dos steakholders, e também ao esforço empregado para atender às suas necessidades, que estão relacionadas com a expectativa de um lançamento de produto ou serviço com as 
características esperadas, obtendo a sinergia da equipe de trabalho para alcançar o resultado (VON HIPPEL, et. al, 2005), conforme mostra a Tabela 7.

Tabela 7 - Variável Latente de Orientação de Valor - Carga Externa Variável Latente de Orientação de Valor

\begin{tabular}{lcc}
\hline Variável Mensurável & Carga Externa & Grau de Influência \\
\hline Há um consenso entre os gestores e funcionários de como criar valor. & 0,842 & 1 \\
Eu recebo informações necessárias de como criar valor. & 0,820 & 2 \\
A empresa busca alternativas de criar valor com outras empresas. & 0,813 & 3 \\
Eu tenho liberdade para desenvolver as respostas adequadas. & 0,801 & 4 \\
Na minha empresa há uma busca ativa por novas ideias e produtos. & 0,787 & 5 \\
A empresa define valores com base nos conhecimentos internos. & 0,779 & 6 \\
Eu entendo que os processos devem focar na criação de valor. & 0,687 & 7 \\
\hline
\end{tabular}

Fonte: Elaborado pelos autores

$\mathrm{Na}$ variável mensurável que avaliou o entendimento que os processos devem focar na criação de valor evidencia-se uma boa relação com a variável latente, mostrando que a organização busca conceituar que inovar é ter assimilado a importância de cocriar valor na percepção dos funcionários fazendo que os projetos sejam trabalhados na perspectiva dos clientes, o que se torna ponto estratégico para a indústria automobilística.

Os resultados da variável latente orientação de valor confirmam a teoria que um processo de criação de valor bem gerenciado é muito benéfico para as empresas e pode gerar inovações que obtenham sucesso no mercado, além de ótimas oportunidades de encontrar outras inovações durante o processo produtivo (IND; IGLESIAS; SCHULTZ, 2013). A variável latente referente à orientação para o mercado apresentou um bom grau de relação com todas as suas variáveis mensuráveis.

Quanto à variável mensurável que avalia se a geração de conhecimento é trabalhada pela empresa como uma ferramenta estratégica, os resultados apontam que está alinhada com o conceito que um dos principais recursos que devem ser desenvolvidos por uma organização é o conhecimento tecnológico e sua capacidade para gerar a inovação, conceito reconhecido tanto na esfera acadêmica como na empresarial (GALENDE, 2006).

Esse resultado direciona a empresa para viabilizar o desenvolvimento do conhecimento de seus colaboradores, o que pode trazer um diferencial competitivo na percepção dos funcionários, conforme evidencia a Tabela 8.

Tabela 8 - Variável latente de orientação para o mercado - Carga Externa

\begin{tabular}{lcr}
\hline \multicolumn{2}{c}{ Variável Latente de Orientação para o Mercado } \\
\hline Variável Mensurável & Carga Externa & Grau de Influência \\
\hline Para minha empresa a geração de conhecimento é estratégica. & 0,768 & 1 \\
Minha empresa tem conhecimento dos clientes e isso garante o futuro. & 0,737 & 0,731 \\
Eu tenho um bom conhecimento da cadeia de valor da empresa. & 0,703 & 3 \\
Minha empresa compreende o ambiente competitivo. & 0,697 & 0,688 \\
Minha empresa encoraja o fluxo de informação. & 0,650 & 4 \\
Quando descobrimos algo sobre cliente utilizamos rapidamente. & 0,607 & 5 \\
Minha empresa tem ideia de qual é o público-alvo dos concorrentes. & 0,521 & 7 \\
O conhecimento na nossa empresa gera vantagem competitiva. & 0,520 \\
Tenho boas ideias que influenciam na competitividade da empresa. & 8 \\
Quando eu sei algo importante informo rapidamente para a empresa. & 9 \\
\hline
\end{tabular}

Fonte: Elaborado pelos autores 
A variável mensurável 'que perguntava aos funcionários que se soubessem de alguma informação pertinente informariam rapidamente a empresa' obteve o valor 0,520 , enquanto na pesquisa realizada por Dobni (2008) essa variável mensurável obteve 0,206.

A empresa automobilística estuda obteve um desenvolvimento melhor nessa variável, já na empresa do setor bancário deve ser feito um trabalho para minimizar o receio de os colaboradores informar aos superiores ocorrências que consideram importantes e que ocorreram fora da organização.

A variável latente contexto da implementação, que finaliza esta análise, apresentou o maior número de variáveis mensuráveis, que se relacionam à proposta de transformar erros em oportunidades, com 0,754 , e à tolerância aos erros, que compõe uma condição fundamental em culturas que apoiam a criatividade, a inovação, e encorajam seus empregados a desenvolver novas ideias (MARTINS; TERBLANCHE, 2003). Os resultados da variável latente contexto da implementação são mostrados na Tabela 9.

Tabela 9 - Variável latente de contexto da implementação - Carga Externa Variável Latente de Contexto da Implementação

\begin{tabular}{lrr}
\hline Variável Mensurável & Carga Externa & Grau de Influência \\
\hline Nossa empresa está sempre à frente das novas tendências. & 0,791 & 1 \\
Minha empresa transforma os erros em oportunidades. & 0,754 & 2 \\
A empresa ajuda romper as barreiras que dificultam a inovação. & 0,751 & 3 \\
Temos sempre novas ideias para mudar os produtos e serviços. & 0,739 & 4 \\
A empresa está preparada para desenvolver novos serviços. & 0,738 & 5 \\
Na minha empresa as ideias fluem naturalmente no dia-a-dia. & 0,729 & 6 \\
Estamos preparados para lançar novos produtos e serviços. & 0,703 & 7 \\
O desempenho da gestão da informação é utilizado para controle. & 0,698 & 8 \\
Nós modificamos nossas ideias para atender os clientes. & 0,691 & 9 \\
O sistema de informação auxilia no processo de comunicação. & 0,675 & 10 \\
A empresa utiliza métricas para medir a inovação. & 0,675 & 10 \\
Estamos preparados para aplicar novos recursos em empreendimentos. & 0,669 & 11 \\
Minha empresa possui recursos humanos e financeiros para inovar. & 0,666 & 12 \\
Gestores têm autonomia para mudar ou até mesmo cancelar projetos. & 0,657 & 13 \\
Na minha empresa registramos o desenvolvimento de produtos. & 0,655 & 14 \\
Minha empresa muda seus serviços para atender os clientes. & 0,654 & 15 \\
A empresa modifica os processos como reação ao mercado. & 0,640 & 16 \\
Nós desenvolvemos produtos e serviços direcionados aos clientes. & 0,626 & 17 \\
Minha empresa tem muitos recursos para gerar a inovação. & 0,546 & 18 \\
Nós percebemos quando os clientes estão insatisfeitos & 0,499 & 19 \\
Nos próximos anos a empresa mudará metade dos seus processos. & 0,409 & 20 \\
\hline
\end{tabular}

Fonte: Elaborado pelos autores

A variável que mostra que a empresa sempre está em busca de novas tendências obteve o valor 0,791 . Esse resultado indica que a empresa está procurando buscar novas tecnologias e incentivando sua implementação.

A combinação de tais contribuições tecnológicas pode proporcionar melhor estrutura para empresa inovar, pois a empresa busca o desenvolvimento para desenvolver a natureza da inovação.

A principal fonte de mudanças determinando os novos desenvolvimentos para gerar inovação tem relação com o acompanhamento das tendências tecnológicas e um acesso maior a fontes de conhecimento, incluindo o conhecimento científico. 
Cria-se, assim, uma mola propulsora para que a cultura da inovação seja implementada em uma empresa e/ou organização tornando-a parte da cultura organizacional (CAMPOS; VALADARES, 2006).

A variável utilizada para medir se a empresa mudará metade de seus processos nos próximos anos, com a relação de 0,409 , mostrou que os colaboradores percebem a atmosfera inovadora da empresa, que trabalha as mudanças com cautela para que não afetem negativamente seus produtos e processos.

Esse resultado se contrapõe à citação de que as organizações que enfatizam esse elemento da cultura de inovação são mais propensas a se envolver tanto em inovações incrementais como em inovações radicais, uma vez que as pessoas compreendem a cultura da empresa e estão geralmente dispostas a sugerir ideias radicais e melhorias nos processos existentes (DOMBROWSKI et. al, 2007).

A análise estatística descritiva das dimensões da cultura da inovação procurou trabalhar as inter-relações entre as variáveis latentes e suas variáveis mensuráveis, trazendo à luz os pontos da cultura da inovação que estão sendo bem desenvolvidos, assim como pontos de melhoria para que a empresa possa ter um conjunto de características da cultura organizacional que tenha uma relação intrínseca com a cultura da inovação (JANIUNAITE; PETRAITE, 2010).

\section{$5 \quad$ Considerações Finais}

Este estudo foi desenvolvido com a intenção de contribuir para a ampliação do conhecimento da cultura da inovação em indústrias do setor automobilístico brasileiro, a partir da aplicação de um instrumento para mensurar a percepção dos colaboradores de uma empresa desse setor. Buscou-se realizar a análise da intenção de inovar como uma proposta da empresa objeto de estudo, e constatou-se que ela oferece uma infraestrutura de apoio à inovação e que a inovação tem influência no trabalho dos colaboradores.

Identificou-se a situação e foi proposta a metodologia de pesquisa desenvolvida por Dobni (2008), que trabalha a cultura de inovação em quatro dimensões: intenção de inovar; infraestrutura de apoio à inovação; influência da inovação; e contexto da inovação. Essas dimensões são divididas em sete fatores.

Com esse cenário idealizou-se uma forma de investigação com a aplicação de um questionário estruturado do tipo survey, desenvolvido por Dobni (2008) aplicado inicialmente no setor bancário e replicado por outros autores, como Moraes et al (2017) em outros seguimentos econômicos. Neste caso, buscou-se identificar a percepção da cultura da inovação dos colaboradores de uma indústria do setor automobilístico.

Realizou-se a análise dos resultados e observou-se que a intenção de inovar da empresa está ligada diretamente à intenção de manter-se competitiva no mercado automobilístico, que depende constantemente de inovações tecnológicas para a redução de seus custos e para atender à demanda dos consumidores.

A pesquisa analisou se os funcionários buscam relacionar a inovação com a cultura da empresa; se percebem a importância da geração de inovação voltada às necessidades dos clientes; e se têm consciência da importância do seu conhecimento para que a empresa possa desenvolver seus processos, atender clientes e estar à frente de seus concorrentes 
Conclui-se, portanto, que ao término deste estudo, o trabalho conseguiu-se responder à questão de pesquisa, já que foi possível verificar qual a percepção dos colaboradores de uma empresa do setor automobilístico sobre a cultura de inovação. Constatou-se, ainda, que os colaboradores pesquisados se sentem parte integrante da cultura de inovação da empresa.

A cultura de inovação está implementada e faz parte da cultura organizacional. É utilizada como uma estratégia empresarial de desenvolvimento da inovação tecnológica, podendo trazer ao longo do tempo vantagem competitiva e econômica.

A pesquisa propiciou a análise de como a cultura da inovação está sendo trabalhada em uma indústria automobilística multinacional instalada no Brasil, e percebeu-se que a empresa gera inovação e tem uma matriz tecnológica de produtos e processos.

Diante do exposto, pode-se concluir que os colaboradores percebem que há cultura de inovação na empresa, e que o estudo foi enriquecedor por ter produzido resultados que podem colaborar para pesquisas futuras sobre a cultura da inovação, quanto para o desenvolvimento de novas soluções para a implementação da cultura de inovação no ramo automobilístico.

Mesmo tendo atingindo o objetivo proposto, esta pesquisa apresenta limitações. Uma delas é que foi realizada apenas nas equipes de engenharia da empresa, porque inicialmente eram essas equipes que tinham como função principal o desenvolvimento e a implementação de projetos e o contato direto com clientes e fornecedores.

Para encerrar as considerações desta torna-se necessário trazer à luz das discussões apresentadas algumas sugestões sobre a continuidade e futuros desdobramentos deste estudo, assim, sugere-se realizar nova aplicação da pesquisa em outras empresas do setor automobilísticos, e propõe-se também realizar a aplicação deste estudo em outras áreas econômicas da indústria, como seguimentos produtivos e econômicos, havendo assim a possibilidade de aprimorar a comparação da cultura da inovação entre os segmentos.

A contribuição acadêmica deste estudo é com relação ao avanço nas pesquisas realizadas no Brasil na área da cultura de inovação e em indústrias do setor automobilístico, pode-se afirmar que o estudo da cultura da inovação em uma indústria do setor automobilismo gerou um documento que pode ser utilizado tanto para pesquisas futuras como também para a concepção de projetos de implementação da cultura da inovação em indústrias deste setor.

\section{Referências}

ABRAMOVAY, R. Desigualdades e limites deveriam estar no centro da Rio+20. Estudos Avançados. São Paulo, v. 26, n. 74, pp. 21-33, 2012. Disponível em: http://www.scielo.br/scielo.php?script=sci_arttext\&pid=S0103-40142012000100003. Acesso em: 30 nov. 2017.

AMABILE, T. M.; BARSADE, S. G.; MUELLER, J. S.; STAW, B. M. Affect and creativity at work. Administrative Science Quarterly, v. 50, n. 3, pp. 367-403, set, 2005. Disponível em: https://journals.sagepub.com/doi/abs/10.2189/asqu.2005.50.3.367? journalCode=asqa. Acesso em: 30 nov. 2017. 
ASSOCIAÇÃO NACIONAL DE FABRICANTES DE VEÍCULOS AUTOMOTORES ANFAVEA. Anuário da Indústria Automobilística Brasileira. São Paulo: ANFAVEA, 2018. Disponível em: http://www.anfavea.com.br/anuario.html. Acesso em: 13 mai. 2019.

BARQUETTE, M. L. M.; COSTA, D. M. A evolução e inovação no mercado automobilístico e sua relevância para competitividade no Brasil. In: DELFOS 2017: Multidisciplinaridade em Inovação - Futuro de Mestres e Doutores. Anais...Belo Horizonte (MG) Universidade Federal de Minas Gerais, 2017. Disponível em:

https://even3storage.blob.core.windows.net/anais/72966.pdf. 30 nov. 2017.

BUENO, B; BALESTRIN, A. Inovação Colaborativa: uma abordagem aberta no desenvolvimento de novos produtos. Revista de Administração de Empresas, São Paulo, v. 52, n. 5, pp. 517-530, set. /out. 2012. Disponível em:

https://www.redalyc.org/articulo.oa?id=155124719004. Acesso em: 17 jul. 2018.

CHESBROUGH, H.Business model innovation: it's not just about technology anymore.

Strategy \& Leadership, v. 35, pp. 12-17, 2007.

DAS, G. S. Preparedness for innovation: an Indian perspective. Global Business Review, v. 4, n. 1, p. 27-39, 2003. Disponível em:

https://journals.sagepub.com/doi/abs/10.1177/097215090300400103?journalCode=gbra. Acesso em: 17 jul. 2018.

DOBNI, C. B. Measuring innovation culture in organizations: the development of a generalized innovation culture construct using exploratory factor analysis. European Journal of Innovation Management, v. 11, n. 4, pp. 539-559, 2008. Disponível em:

https://www.emeraldinsight.com/doi/abs/10.1108/14601060810911156, Acesso em: 17 jul. 2018.

HAIR, J. F.; SARSTEDT, M.; RINGLE, C. M.; MENA, J. A. An assessment of the use of partial least squares structural equation modeling in marketing research. Journal of the Academy of Marketing Science, v. 40, n. 3, pp. 414-433, 2012. Disponível em: https://link.springer.com/article/10.1007/s11747-011-0261-6. Acesso em: 30 nov. 2017.

IND, N.; IGLESIAS, O.; SCHULTZ, M. Building brands together: Emergence and outcomes of co-creation. California Management Review, v. 55, n. 3, pp. 5-26, 2013. Disponível em: https://www.researchgate.net/publication/259729369_Building_Brands_Together_Emergence and_Outcomes_of_Co-Creation. Acesso em: 30 nov. 2017.

JANIUNAITE, B. PETRAITE, M. The relationship between organizational innovative culture and knowledge sharing in organization: the case of technological innovation implementation in a telecommunication organization. Socialiniai Mokslai, v. 3, n. 69, pp. 14-23, 2010.

Disponível em: http://www.anpad.com.br. Acesso em: 24 jul. 2018. 
MARTINS, E. TERBLANCHE, F., Building organizational culture that stimulates creativity and Innovation. European Journal of Innovation Management, v. 6, n. 1, pp. 64-74, 2003.

MONTEIRO, I. A. Comportamentos do líder inovador no setor do turismo. $376 \mathrm{f}$. Tese (Doutorado em Psicologia das Organizações) Faculdade de Ciências Sociais e Humanas. Universidade do Algarve. Faro/Portugal. 2008.

MORAES, M. B.; MIRANDA, M. A. S.; OLIVEIRA, E. A. A. Q.; SANTOS, E. M. Cultura de Inovação em Micro e Pequenas Empresas dos Setores Aeronáuticos e de Tecnologia da Informação. EXACTA (ONLINE), v. 15, pp. 441-456, 2017. Acesso em: 13 julho de 2018. MOREM, R.C.; HENKIN, H. Economia e Sociedade, Campinas, v. 25, n. 2 , p. 457-487, ago. 2016.

NARANJO-VALENCIA, J. C.; JIMÉNEZ, D. J.; SANZ-VALLE, R.Es la cultura organizativa un determinante de la innovación en la empresa? Cuadernos de Economía y Dirección de la Empresa, v. 15, n. 3, p. 63-72, 2012.

OECD - Organization for Economic Co-operation and Development, Manual de Oslo Diretrizes para coleta e interpretação de dados sobre inovação, OECD - tradução FINEP, Brasília, 2006. Disponível em: https://www.finep.gov.br/images/apoio-efinanciamento/manualoslo.pdf . Acesso em: 13 fev 2019.

PEREZ, C. Technological revolutions and techno-economic paradigms. Cambridge Journal of Economics, v. 34, p. 185-202, 2009.

RAMASWAMY, V. Leading the Transformation to Co-Creation of Value. Strategy and Leadership. v. 37, n. 2. pp. 32-37. 2009.

SABAINI, W.T. Cultura de Inovação em pequenas e médias empresas inovadoras. 2013. 268 f. Tese (Doutorado em Administração) - Centro de Ciências Sociais e Aplicadas, Universidade Presbiteriana Mackenzie, São Paulo, 2013.

SERRA, F. A. R., FIATES, G. G., ALPERSTEDT, G. D. (2007). Inovação na pequena empresa: um estudo de caso na Tropical Brasil. Journal of Technology Management \& Innovation, v. 2, n. 2, pp. 170-183. 2007.

SCHUMPETER, J.A. The Theory of Economic Development. Harvard University Press, Cambridge Massachusetts, 1934.

TIGRE, P.B. Gestão da Inovação: A Economia da Tecnologia no Brasil. Elsevier, Rio de Janeiro, 2006.

VARELLA, S. R. D.; SILVA JUNIOR, M. T.; MEDEIROS, J. B. S. O desenvolvimento da teoria da inovação schumpeteriana. In: XXXII Encontro Nacional de Engenharia de 
Produção - ENEGEP, 2012, Bento Gonçalves. O desenvolvimento da teoria da inovação schumpeteriana, 2012.

WITELL, L., KRISTENSSON, P., GUSTAFSSON, A., LÖFGREN, M., "Idea generation: customer cocreation versus traditional market research techniques", Journal of Service Management, v. 22, n. 2, pp.140-159, 2011.

WOOD JR, T; P. CALDAS. Empresas brasileiras e o desafio da competitividade. Revista Adm. Empresa, São Paulo, v.47, n.3, pp.1-13, sept. 2007.

ZAMBERLAN, Luciano; SPAREMBERGER, Ariosto; DARONCO, Edimara; BLUME, Marcelo. Gestão estratégica do ponto de venda. - Ijuí: Ed. Unijuí, 2010. 